\title{
Brasergasilus guaporensis sp. n. (COPEPODA: ERGASILIDAE) DAS BRÂNQUIAS DE Leporinus fasciatus (BLOCH, 1890) (CHARACIFORMES: ANOSTOMIDAE) DA AMAZÔNIA BRASILEIRA.
}

\author{
José Celso O. MALTA (1)
}

RESUMO - Brasergasilus guaporensis sp. n. (Copepoda, Poecilostomatoida, Ergasilidae) é proposta. Os espécimens foram coletados dos filamentos branquiais de Leporinus fasciatus (BLOCH, 1890) do Rio Guaporé, próximo a Pimenteiras, Rondônia, Brasil. A nova espécie difere das outras conhecidas do gênero no formato da garra da antena e na presença de ornamentações no somito genital duplo e abdômen.

Palavras chave: Copepoda, Brasergasilus, Ergasilidae, Amazônia, espécie-nova.

Brasergasilus guaporensis sp. n. (COPEPODA: ERGASILIDAE) from the gills of Leporinus fasciatus (BLOCH, 1890) (CHARACIFORMES: ANOSTOMIDAE) from the Brazilian Amazon.

ABSTRACT - Brasergasilus guaporensis sp. n. (Copepoda, Poecilostomatoida, Ergasilidae) is proposed. The specimens were collected from the gill filaments of Leporinus fasciatus, from Guaporé River, near Pimenteiras, Rondônia, Brazil. The new species differs from the others known for the genus by the shape of the claw of the antenna and ornamentation on double genital somite and abdomen.

Key-words: Copepoda, Brasergasilus, Ergasilidae, Amazon, new species.

\section{INTRODUÇÃO}

São três as espécies conhecidas de copépodos do gênero Brasergasilus: $B$. jaraquensis Thatcher \& Boeger, 1983, a espécie tipo, coletada no rio Solimões, nas proximidades de Manaus, dos filamentos branquiais de Semaprochilodus insignis (Schomburgk, 1841); B. anodus Thatcher \& Boeger, 1983 coletada no rio Tocantins, Estado do Pará, dos filamentos e rastros branquiais de Anodus elongatus Spix, 1829 e B. oranus Thatcher \& Boeger, 1984 coletada no rio Solimões, nas proximidades de Manaus, dos filamentos e rastros branquiais de A. elongatus. As espécies do gênero Brasergasilus são endêmicas à região Neotropical (THATCHER \& BOEGER, 1983 e 1984).

Abergasilus amplexus Hewitt, 1978, a única espécie descrita do gênero é endêmica à região Australiana, foi coletada dos filamentos branquiais de Retropinna retropinna (Richardson, 1848), Anguilla australis Richardson, 1848 e mais nove espécies de teleósteos de lagos eurihalinos da Nova Zelândia (HEWITT, 1978). O macho da espécie foi descrito por JONES (1981).

Thatcher \& Boeger (1983) criaram a subfamília Abergasilinae onde incluíram o gênero Abergasilus e o Brasergasilus por possuirem carac-

(') Departamento de Biologia Aquática, Instituto Nacional de Pesquisas da Amazônia, Caixa Postal 478, Manaus, Amazonas, Brasil, CEP 69011-970. 
teres apomórficos comuns: antena com dois segmentos e com a garra muito desenvolvida, tamanho do corpo reduzido e três pares de pernas.

Neste trabalho é descrita a quarta espécie do gênero Brasergasilus coletada na região Neotropical.

\section{MATERIAL E MÉTODOS}

O material foi coletado no Estado de Rondônia, região noroeste do Brasil, durante o período de 28 de novembro de 1983 a 25 de setembro 1985 .

Os peixes foram identificados, pesados e medidos, As brânquias e vísceras foram removidas e fixadas em formal $10 \%$.

Os copépodos foram retirados dos filamentos branquiais utilizando-se finos estiletes, microscópio estereoscópio e transferidos para formol 5\%. Lâminas permanentes, com montagem total dos copépodos, foram preparadas usando o método de Thatcher, denominado "HYP" (publicado em Monoculus: Copepod Newsletter, n.15 de novembro de 1987). Cada indivíduo foi retirado da solução aquosa (formol 5\%) e mantidos em álcool $70 \%$. A seguir, colocados em solução corante, Eosina e Orange-G, Posteriormente colocados em fenol e em seguida em salicilato de metila. Finalmente, foram montados em bálsamo do Canadá entre lâmina e lamínula e colocados em estufa à $70^{\circ} \mathrm{C}$.

Os desenhos foram feitos com o auxílio de câmara clara. As medidas foram obtidas com uma ocular micrométrica e expressas em micrômetros, são dadas as amplitudes seguidas pela média entre parênteses.

Os peixes foram depositados na Coleção Ictiológica do Instituto Nacional de Pesquisas da Amazônia, em Manaus.

Os tipos foram depositados nas coleções do Instituto Nacional de Pesquisas da Amazônia (INPA-CR), Manaus, Amazonas e Museu de Zoologia da Universidade de São Paulo, (MZUSP), São Paulo

\section{RESULTADOS}

Ergasilidae Nordmann, 1832

Abergasilinae Thatcher \& Boeger, 1983

Brasergasilus guaporensis sp. $\mathrm{n}$.

Material examinado:

Holótipo: fêmea (INPA-CR 611), dos filamentos branquiais de Leporinus fasciatus, coletado no Rio Guaporé, próximo a Pimenteiras (13 $28^{\prime} \mathrm{S}$; $61^{\prime \prime}$ 4'W), 29-XI-1984, em lâmina. Parátipos: 4 fêmeas (INPA-CR 612 a - d) e 2 fêmeas (MZUSP 10442 a e b) em lâmina; 420 fêmeas INPA-CR 613 e 10 fêmeas MZUSP-10443, em formol $5 \%$, coletadas dos filamentos branquiais de cinco Leporinus fasciatus da localidade tipo, 29/30-XI1984. Todos coletados por J.C.O. Malta.

Fêmea: Corpo (Figs.1 e 2) comprimento total 301-382 (335). Prossomo mais largo que o urossomo, largura do corpo 112-150 (125). Largura máxima ocorrendo na parte anterior do segundo somito torácico. 


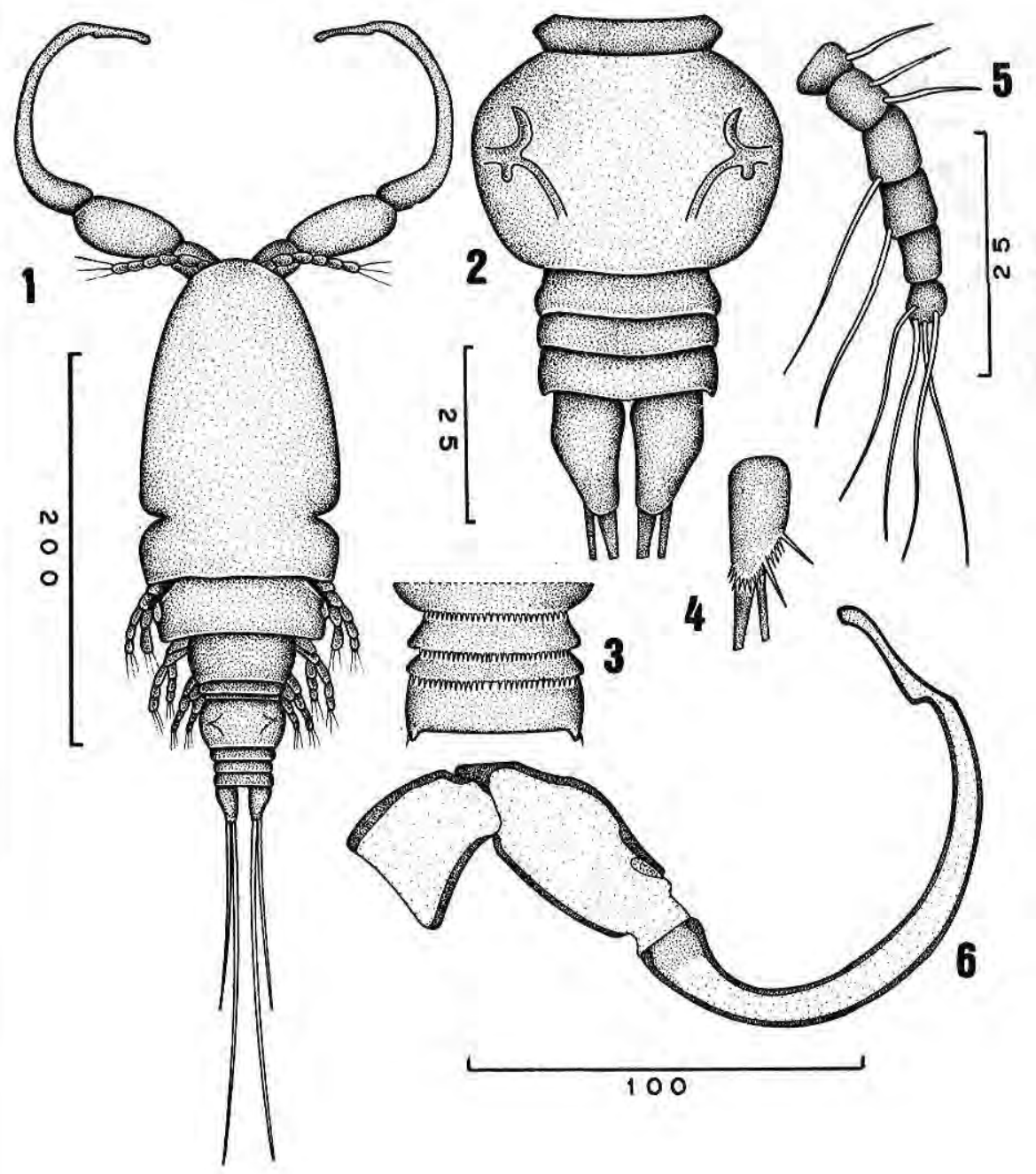

Figuras 1-6. Brasergalis guaporensis sp. n. (fêmea) 1 - vista dorsal (somito 6, somito genital duplo, somitos abdominais e ramos caudais). 3 - porção distal do somito genital duplo, somitos abdominais (vista ventral), 4 - ramo caudal (vista ventral), 5 - antênula. 6 - antena (medidas em micrômetros). 
Cefalotórax (Fig. 1) medindo 150-210 (185) de comprimento e 112150 (125) de largura, subovóide, margem anterior arredondada alarga-se suavemente até chegar à parte final do cefalossomo, onde afina bruscamente formando uma cintura no local onde há a segmentação parcial com o primeiro somito pedígero, volta alargar-se e na porção anterior deste somito tem a largura máxima. A partir deste ponto vai suavemente afilando-se até a margem posterior do cefalotórax. Margens laterais arredondadas. Area metassomal (Fig.1) com três somitos pedígeros (somitos 2, 3 e 4 ) e somito 5 sem pernas natatórias, todos claramente separados e decrescendo suas larguras gradualmente na direção terminal.

Urossomo (Figs. 1 e 2) menor que a metade do comprimento do prossomo e somito 6 sem pernas natatórias. Somito genital duplo (Figs. 1 e 2) suborbicular, mais largo que comprido, comprimento 25-32(28), largura 25-45(35). Margens laterais arredondadas. Margem posterior ventral com uma fileira de pequenos espinhos. Somitos abdominais (Figs. 1, 2 e 3): somitos abominais 1 e 2 subretangulares e com as margens posteriores ventrais com uma fileira de pequenos espinhos; somito abdominal 3 (anal) sub-retangular e com as margens laterais se projetando posteriormente terminando em um espinho de cada lado. Ramos caudais (Figs. 1, 2 e 4) subtriangulares, ambos equipados com uma seta longa e uma curta na margem distal, duas setas reduzidas na margem lateral externa e uma fileira de pequenos espinhos na margem posterior ventral.
Antênula (Fig. 5) comprimento 50-60(58) e largura 10-15(11), cilíndrica, com seis segmentos, carregando nove setas simples e com a fórmula setal: 1 - 2 - 1 - 1 - 0 - 4. Antena (Fig. 6) com dois segmentos. Segmento 1 sub-retangular e o menor, comprimento 45-53(48), largura 22-36(29); segmento 2 o mais robusto, com uma pequena elevação mediana na margem externa, comprimento 54-67(58), largura 2027(23); o processo distal é uma garra fina, curva e longa, com uma reentrância, em forma de flecha unilateral no quarto distal, seguida de uma ligeira concavidade interna e uma pequena dilatação terminal. A relação entre os segmentos é 1,0 - 1,2 - 3,2.

Peças bucais (Fig. 7): mandíbula com dois segmentos, longa, segmento basal estreito na parte proximal, sem ornamentações e fortemente preso ao cefalossomo, alarga-se abruptamente para mais que o dobro, com esta largura avança até a região mediana, quando começa a afilar-se e neste ponto origina-se o palpo mandibular, falciforme e com uma série de minúsculos dentes na margem posterior, o processo basal continua, afila-se e distalmente forma uma lâmina falciforme com minúsculos dentes na margem posterior. Maxílula ausente. Maxila provavelmente com dois segmentos, alongada, segmento proximal sem ornamentações, muito largo e fortemente preso ao cefalossomo, segmento distal formando um ângulo reto, com cerdas na extremidade distal.

Pernas (Figs. 8 - 10) providas de setas plumosas. Perna I (Fig. 8) 


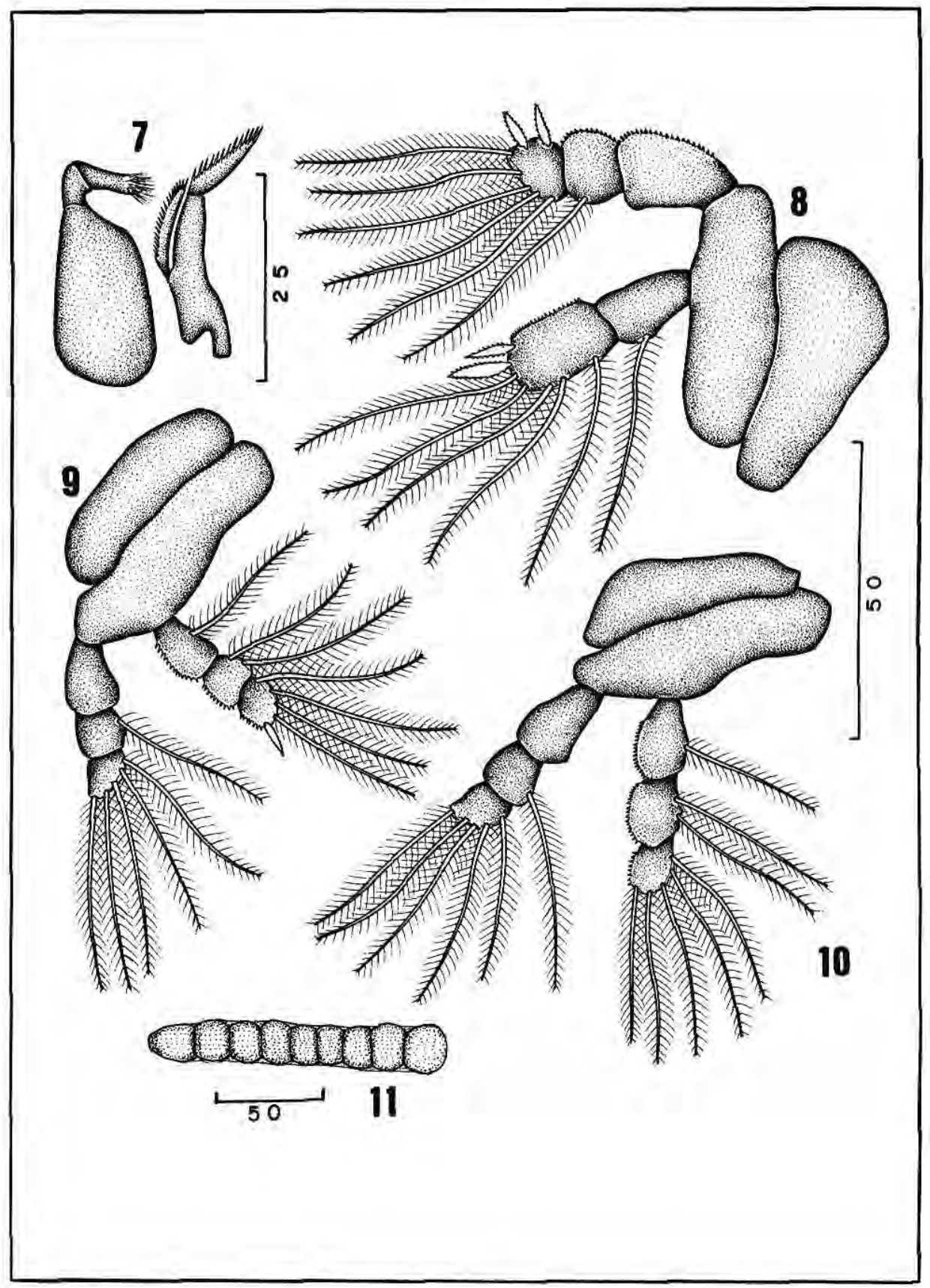

Figuras 7-11. Brasergasilus guaporensis sp. n. (fêmea). 7 -peças bucais. 8 - perna I. 9 perna II. 10 - perna III. 11 - saco de ovos (medidas em micrômetros). 
endopodito com dois segmentos e exopodito com três. Segmento 1 do endopodito em forma de clava e com uma seta; segmento 2 sub-retangular maior e mais largo que o 1 , robusto, com cinco setas, dois espinhos pectinados e uma fileira de pequenos espinhos na margem externa. Exopodito segmentos 1 e 2 com uma fileira de pequenos espinhos na margem externa. Segmento 1 o maior e mais robusto, sendo duas vezes o comprimento do 2 e três do terminal, segmento 2 suborbicular e com uma seta; segmento 3 o menor, subtriangular, com cinco setas e dois espinhos pectinados. Perna II (Fig. 9). Ambos os ramos de três segmentos. Todos segmentos do endopodito, com uma fileira de pequenos espinhos na margem externa. Segmento 1 o maior e com uma seta; segmento 2 com duas; segmento 3 com quatro e um espinho. Segmento 1 do exopodito sem ornamentações; segmento 2 com uma seta; segmento 3 com cinco setas.

Perna III (Fig. 10). Ambos os ramos de três segmentos. Todos os segmentos do endopodito com uma fileira de pequenos espinhos na margem externa. Segmento 1 do endopodito com uma seta lateral; segmento 2 com duas; segmento 3 com cinco. Segmento 1 do exopodito, o maior e em forma de clava e sem ornamentações; segmento 2 com uma seta; segmento 3 o menor e com cinco setas.

\section{Pernas IV e V ausentes.}

Saco de ovos (Fig. 11) com uma única série de ovos que variam numericamente, de oito a nove. Macho: Desconhecido.
Etimologia: O nome específico deriva do nome do rio onde os exemplares foram coletados, rio Guaporé.

\section{DISCUSSÃO}

B. guaporensis sp. n. é a quarta espécie descrita do gênero Brasergasilus. Apresenta as características do gênero: antena com dois segmentos, e uma grande garra; tórax com quatro somitos livres, maxílula ausente, três pares de pernas (pernas 4 e 5 ausentes). Além disso, B. guaporensis tem o mesmo número de segmentos, nos três pares de pernas, como as demais espécies do gênero. As peças bucais são muito semelhantes, principalmente a forma $\mathrm{e}$ estrutura da maxila. O comprimento total de Brasergasilus guaporensis varia de 301 a 382 , é semelhante ao de $B$. anodus (320 a 370$)$ e ao de $B$. jaraquensis ( 340 a 410 ) e um pouco menor que os de $B$. oranus (420 a 510 ).

Comparando-se o comprimento do cefalotórax de B. guaporensis com o de outros ergasilídeos, verifica-se que, nesta espécie, corresponde a $54,0 \%$ do comprimento total, sendo diferente das proporções encontradas para as outras três espécies do gênero: $B$. jaraquensis e B. anodus $51,0 \%$ e $B$. oranus $61,0 \%$. A mesma proporção é encontrada em Acusicola pellonidis Thatcher \& Boeger, 1983 que é de outra subfamília, a Acusicolinae.

As características que separam $B$. guaporensis das demais espécies do gênero são: relação comprimento total versus comprimento do cefalotórax; ausência de ornamentações e estrutura da 
garra, na antena; ornamentações do somito genital duplo e ramos caudais; ausência de espinhos e cerdas no segundo e terceiro exopoditos; saco ovígero com uma única série de ovos.

A antena de B. guaporensis apresenta uma adaptação no quarto distal da garra, tornando-a mais eficiente para a fixação no filamento branquial do hospedeiro. Consiste de uma reentrância, na margem posterior, similar à ponta unilateral de uma flecha. Como neste gênero a garra penetra nos tecidos, esta estrutura proporciona ao copépodo uma fixação mais eficiente. Esta adaptação é única entre os ergasilídeos neotropicais.

Os índices parasitários de $B$. guaporensis de Leporinus fasciatus do rio Guaporé, na época de coleta foram: prevalência $50,0 \%$; intensidade entre 8 2400 copépodos por peixe; intensidade média 499,0 e abundância 249,0 .

\section{Literatura Citada}

HEWITT, G. C. 1978. Abergasilus amplexus gen. et sp. nov. (Ergasilidae: parasitic Copepoda) from fishes in Lake Ellesmere, New Zealand. N. Z. Jour: Mar. Freshw. Res, 12(2):173-177.

JONES, J. B. 1981. Abergasilus amplexus HEWITT, 1978 (Ergasilidae: Copepoda) from New Zealand, with a description of the male. N. Z. Jour. Mar. Freshw. Res, 15:275-278.

THATCHER, V. E.; BOEGER, W. A. 1983. The parasitic crustaceans of fishes from the Brazilian Amazon. 5. Brasergasilus gen. nov. (Copepoda: Cyclopidea). A "three-legged" ergasilid with two new species and the proposal of Abergasilinae subfam. nov. Acta Amazonica, 13(1):195214.

1984. The parasitic crustaceans of fishes from the Brazilian Amazon. 5. Brasergasilus oranus n. sp. (Copepoda: Cyclopidea) from Anodus elongatus Spix. Rev. Brasil. Biol., 44(4):395-401. 